\title{
How Consumers' Skepticism is Derived from Deceptive Advertisements
}

\author{
Shaista Kamal Khan*, Hina Fatima***, Syed Waqas Hussain****
}

\begin{abstract}
This paper aims to explore how consumer behaviour is derived from deceptive advertising and its effect that is consumers' skepticism. The advertisement has a significant influence on every single person's life and shapes the consumer's perception. In this study, phenomenological interviews were conducted with three mature females and three males consumers by asking predetermined open-ended questions. The questions had been made to determine the thoughts and feeling about the unlawful, untrue, and mendacious advertisements. The current research shows these symbolic metaphors and highlights the essential meanings that each informant ascribed consumer encounters. All relevant themes are identified after conducting interviews with participants through data analysis and are further discussed in the results and findings. All findings are interlinked also supported and consistent with earlier studies that are related in this context. The qualitative study ends with some recommendations to companies that think about their consumers and also follow ethical advertising practices.
\end{abstract}

Keywords: Deceptive, Advertisement, Consumer, Skepticism

JEL Classification: $M 30, M 37$

\section{INTRODUCTION}

It is not new to the market to deceive and studying deception and also the ways to handle dishonesty is essential for social life. The deception in commercials is an ambiguous result that causes prospects to encounter disbelief regarding the presented product. In the marketing context, Polly (1986) researched deception, and he was one of the first who researched it. He discovers that negative advertising can lead consumers not to trust the company's future advertisements (Aghakhanni \& Main, 2019; Ukaegbu, 2020). It is shown in the research, brands that follow ethical practices in their advertisement tend to have a strong bond between brand and customers relationship. Likewise, brands that follow unethical practices could become dreadful horribly. The relationship with the customer can be destroyed badly if a business performs unethically; this can harm the company's brand equity and its product and services

Correspondence:

*Assistant Professor, Jinnah University for Women, Karachi.shaistakamalkhan@gmail.com

**Scholar, Jinnah University for Women, Karachi, binafatima_90@yahoo.com

${ }^{* * *}$ Scholar at Jinnab University for Women, Karachi 
(Mpinganjira \& Maduku, 2018). Online hotel feedbacks are high in degree of privacy so, these are easier sources to spread mendacious information. Managers of hotels and also employed individuals are included in this socially unrequired process of evaluation manipulation. Such s, in the region of Asia-pacific the GM of communications one of the French hotel chains the Accor group was captured uploading 100 good responses for their hotel from all over the world. However, in the United States, the Attorney General of New York heavily fined 19 companies for a flooded online platform with false responses on different websites like Yelp, City Search, and Google. As a result of these unlawful practices, the hotel customers might experience greater disbelief (Ahmad \& Sun, 2017).

Grab the attention through truth called advertisement; this word originated from the Latin language specify as "adventure". The response of viewers and the listeners made by the advertisement towards specific products and services. Similarly, advertisements are meant to generate awareness regarding products by communicating with their valuable prospects. Therefore, presently advertisement is the most reliable source of influencing and persuading the behavior of customers (Halamata, 2013).

The wide and deceptive commercials are highlighted as untruthful statements that are utilized in the commercials. Contra-wise, this belief has revived now because several laws have been established regarding this over time. Monitoring authorities have been formed by significant laws and agreements regarding unlawful advertisements. Presently, these kinds of unlawful activate are typical in different countries. In the last past years of the 70s, there is a fragrance manufactured company that used to follow the unlawful and mendacious practices it reaches to its targeted audience and also to increase sales of their product. Moreover, the same company claimed their fragrances could charm men, these types of claims were made to attract the customer's attention towards their product although they were falsifying statements (Ukaegbu, 2020; Ohlhausen, 2014; Reichert \& Lambiase, 2013).

Same as the advertisements of energy drink products claims that their products can instantly give power to a person who consumes the drink. Similarly, many flavored milk companies claim, if your kids take their product so, their children can grow up. The disheartening thing is that there are celebrities who promote this kind of product to customers. However, the truth is that these celebrities never used these products, which they promoted to customers with unlawful claims like, customers can have shiny skin and long hairs as they have. However, the matter of fact is whatever is shown in the commercials are just the area of makeup. (Syed, 2014).

Multiple researchers have described the worst characteristics of deception in an advertisement through numerous sources. Also, other researchers expose that the description of deception is "mendacious commercials tend to manipulate the falsehood or truth by its performance. Advertising agencies are considering now that, not misleading and delivering statements, the brand develops trust by communicating with the customers such as prospects have no falsifying trust related to the products which are advertised (Ali et al., 2011; Chaudary et al., 2015).

\section{Limitations:}

This research is limited to some extent, such as; restricted by the time and social media element was neglected. Only TV advertisements were selected. Due to the limitations of time, 
six participants were interviewed, and the interview time duration was 40-50 minutes used to gather relevant information related to the topic. The themes of this research could be extended in the future, but in the current study, only six themes are considered. The data was gathered from the participants who belong to Karachi, Pakistan only.

\section{Theories of Advertising:}

One of the finest and oldest theories of marketing is called AIDA (Awareness, Interest, Desire, and Action). This theory reveals how customers connect and perceive advertisements and how they react towards them. All the marketing communications that brands conduct with their customers is done through AIDA. The advertisement plays a vital role in success, so it has to designed in a way that consumer moves towards all these four phases, one by one that all are equally significant. This model suggests that advertising should be memorable, and a convincing message should stimulate customers to take action (Amah, Ogunnaike, Ayeni, \& Ojo,2017; Kotler, 2011; Fortenberry \& Mcgoldrick, 2019).

When talking about Consumers' skepticism and is derived from deceptive advertisements, the second theory supports this concept, such as expectancy disconfirmation theory (Oliver, 1997). This theory suggests that judgments of perceived expectations (also the results of satisfaction) are developed by each person's psychologically through its process regarding their past experiences (i.e., what was expected from that experience), performance or quality perception (i.e., what was encountered), and expected disconfirmation and confirmation regarding the performance or quality experienced (Morgeson, 2012). The theory of EDT has been supported to describe the alteration between performance measured objectively and perceived performance, also to recognize the government's performance judgments of citizens generally. This theory contains the public service citizen judge rely on implied difference the quality of service along with past expectations, and the supporting evidence is there in public research management (Van Ryzin, 2006; James, 2009; Morgeson, 2012; Grimmelikhuijsen \& Porumbescu, 2017).

The EDT's fundamental aim is disconfirmation and confirmation of each person's past anticipations, which can apparent whether as negative disconfirmation (i.e., dissatisfactory than expected performance) or positive disconfirmation (i.e., more satisfactory than expected performance), last but not the least the satisfactory outcome related to an experience. Concerning this theory, our study is based on the above-mentioned points, as shown in the results also that the customer's prior experience is essential because customers expect a lot from their brand. The study presented the customer's experience related to their respective brands. Once the customer's expectation developed, they tend to expect more and more such as good quality, comfort, reliability, quality assurance, and consistency from the brand. (Roch \& Poister, 2006; Flitenborg, Gaardboe \& Sigsgaard, 2017; Au \& Tse, 2019).

\section{Problem Statement:}

TVCs play an essential role in promoting consumer products. Product details with different appeals are being communicated to prospective customers. Sometimes companies exaggerate their product appeals to boost their sales and enhance their brand image. These appeals either rational or emotional, sometimes overbuild customer expectations. The emotional appeals may divert customers from reality towards fantasy that at times becomes hazardous to society. The 
failure of conformance with quality results in consumer dissatisfaction and skepticism about a particular brand image (Shahzad et al., 2016; Alshurideh, Al Kurdi, Abu Hussien \& Alshaar, 2017).

Online commercials play an essential role in the purchase of weight loss products. Hence, specialists, doctors, and research scholars have highlighted some after-effects of these products on customers' health by deceptive advertisements. Some studies also highlighted that the rate of deceptive commercials is too high in the United States relative to other regions. (Chelliah \& Swamy, 2018).

Past researches demonstrated and also suggested that the outcome of commercials based on skepticism towards the attitude of customers regarding the brand and its reactions as per the commercial's reliability should find out and studied deeply (Raziq et al., 2018; Rao \& Wang, 2015). According to Lim, Chock \& Golan (2018) that future research should be trying to test these variables by using the alternative method and also has suggested that the current research can be replicated in different cultures or countries.

\section{Research Questions}

The research questions of the current study are as follows.

1 What is the concept of deceptive marketing?

2 Why is it important to practice ethical marketing?

3 How deceptive advertisements influence consumers' behaviour and create consumer's skepticism?

\section{Significance of the Study}

The primary emphasis of this research is to explore the deceptive marketing practices in Pakistan and their relevant effects on consumer behaviour or reason consumer's skepticism. This study will be helpful for marketers to identify why is it important to practice ethical marketing? It will also tell how issues related to deceptive marketing can be resolved? So, this research is helpful to build a real brand image, and that will affect the company's profitability, performance, and market shares.

\section{LITERATURE REVIEW}

The deception is the action by a marketer that is misleading to the customers who indulge themselves in that setting of purchase or making a purchase decision of any product or services of the company is conducting unethical advertising practices. Moreover, the medium of conveying messages that are mendacious in reality to effect or change the purchase choices of customers and customers are not known of this fact called deceitful platform of communication (Sahni \& Nair, 2020). A previous study highlighted the impact of skepticism advertisement on consumer perception related to purchasing intention about weight loss product and also discovered the high and moderate aspects of deception (Lim, Chock \& Golan, 2020)

Business and brands use unethical claims and spread wrong claims and news about its products and services just to compete with other brands, Research in the field of academics 
have concentrated less focus to the results of deceptive practices in the marketing, impacting of both victims and offenders. Instead, they must be focused on promoting the right positive tactics of marketing. On the other hand, exploring the impact of unlawful marketing practices are also essential; deceptive knowledge is sometimes quieter than legal information (Song, Kim, Lee \& Jang, 2019).

In this era, the deception by the advertisement is standard practice. Through several communication channels that have massive audiences such as TV, radio, Billboards, sigh boards, Transportation satellite channels, etc. these many fraudulent advertisers promote their deceptive advertisements. Brands sell some of the products that are false for critical diseases such as diabetics and cancer etc. offered invaluable guarantees through advertisement by several companies that promise to give treatment to critical diseases in a short time (Hayder, 2017).

According to Shahzad and Kausar (2016), the customers need to evaluate and develop rational decisions about the product purchase, and for that, they need comprehensive and accurate information related to the product. Some of the deceptive advertising tactics affect consumer's thoughts that represent the impact of customer's emotional reactions and attitudes. Misleading commercials are frequently used to exercise ambiguous ads, many times telling lies to customers, delivers fallacious specifications, and showing deceitful information about products.

How different brands purposely build misperceptions in promoting the goods, without knowing the value of results that can damage their company's image in the corporate sector and affect worst on their company's performance. Many works of literature emphases the wost results that mendacious commercials could have on prospects. Businesses may utilize mendacious commercials to made products more attractive towards prospects or to create misconceptions and therefore to persuade consumption; in many cases, businesses simply discard information and never showed it visibly, as shown in the KFC's case (Passarini, Cavicchi, Santini \& Mazzantini, 2017).

The behavioral feedbacks of prospects on faulty and ambiguous advertising of goods and services makes customers hurt emotionally and mentally too. It is witnessed that customers who have inadequate money to purchase products get hurt they get revealed to deception. It ultimately hurt customers financially and emotionally to be distressed and scientifically that has proven that customers felt incapable, with no self-esteem and isolated to the enjoyment of life, unhappiness, or extreme sadness and distress (Chaudary et al., 2015).

Today's customers are educated enough to identify and distinguish between deceptive and non-deceptive advertisements, so if an advertiser tries to manipulate customers by their falsifying acts so practically, they cannot do these days. The deception is the wrong act to convincing the other by falsehood and influence the consumer judgment about product purchase, and this is also destroying the accuracy of consumer's credence, but this is not important. The important point is the deceiver should communicate his victim with false information or false claims that are the cause of false judgment leads towards the purchase (Bin Nooh et al, 2014; Cohen \& Shlomo, 2018; Krstis \& Saville, 2019).

Many television advertisements are created by a scam and purposely promote false truth regarding goods. However, the matter of fact is these above practices invalid and impractical 
approaches. This is an invalid practice that builds consumer's skepticism by showing wrong statements in advertisements that do not match with the quality and the performance of the product. Human lives are affected substantially by these types of commercials. Customers are deliberately convinced daily and persuaded through wrong statements by the manufacturer to purchase their branded products. These inefficient processes are invalid, and also the society is supposed you be only fair because unlawful ads instigate customers to buy the company's products (Maicibi and Abdullahi, 2013; Iqbal \& Siddiqui, 2019).

In product marketing, commercials play an essential role that promotes dishonest promotion regarding the product's size, features, geographical properties, quantities, and qualities related to products and services. Inaccurate promoted TV commercial usually have untrue statements which are presented as true statements by manufacturer and companies' owners regarding their specific product. Through those mendacious commercials processes, marketers are supposed to deceive a particular group of customers purposely and the result is wasting money, and also, they do not meet their needs (Liepinyte \& Daugeliene, 2012; Iqbal \& Siddiqui, 2019).

The emotional appeals that a category in which this is well known and characterize as playing with customer's emotions and commonly loom them along with scares or committing astonishing outcomes, whether those are doubtful. Goods such as nourishment tablets and health care machines sold via ads or TV sometimes commits marvelous fallouts and encourages through promoting expectations and visualizations of pleasure. Marketing procedures that do not contain moral values may result in customers' disappointment, negative advertisement, and untruthful, the wrong image of the company all that are unlawful actions (Mahmood, 2013). One more set of advertisements can be discussed in this regard goods that are so-called "conventionally made". The commercials notify the materials and the process that uses in past days and denotes that utilization for the advertisement of the goods. However, these statements are hardly true. A very similar process of exploitation can be discovered in a category called "green advertisement". This category reveals that goods are being made for environmental advantages that are also known as the "greenwashing' that betrays and misguides the prospects (Khan et al., 2015; Sarah \& Jenefa, 2020).

According to Danciu (2014), the excessive variety of misrepresentative and dishonest statements approached by the brands that do not contain green goods attempt to deceive prospects. Entire facts along with the cunning character that employs in commercials do not matter the goods can be involved in given classes: unclear or confusing facts statements that neglect substantial knowledge important for analyzing their honesty or nationality, entitlements that fabricate or wrong lies, and also multiple mixtures of the earlier set of categories. Deceptive advertisement severely impacts the validity of business by minimizing investment and complete confidence in goods. Customer trust can build or demolish a market. Likewise, the percentage of deceptive advertising increases the customer's retention decrease. This decrease in the relationship between business/customer can be longer neglected if the market is large (Hayder, 2017; Lanjekar \& Tilak, 2019).

The prior experience and knowledge of customers about the specific products remarkably help in modeling the perception and decision in the process of purchasing decisions of customers and also affect the evaluations. The primary purpose of the advertisement is to spread awareness related to products and to convey information to its prospects. Whenever customers watch ads on TV or print media so, those commercials impact the customer's behavior regarding 
the characteristics and information of the products so, this is regarding the goods perceived advantages, perceived quality, the perceived origin of the product, price perceived, perceived product value, company perceived image and product popularity (Liligeto et al., 2014).

Another earlier study is also explained, that mendacious advertisement significantly distresses the choices of consumers related to whatever they purchase. These kinds of commercial develop unexpected and untrue facts about the product's quality. Similar commercials do not only distort the preferences of the customers but also are dishonest. Likewise, Mahmood (2013) researched and revealed that spoken and text untruthful commercials give knowledge about all products specification except the facts and exclude some descriptions from commercials. Various cases prove that the commercials mislead, omit, guides wrongly, and interpret wrong material specification regarding services and the products (Jeeva, 2016; Ariyadasa, 2019). Zedan \& Salem suggested (2016) Customers experience the kind of advertisements daily which creates confusion and misleads the customers the falsifying words that impact lousy impression regarding the advertised products and its manufacturer because they use a famous brand's name.

Such commercials can connect the customer's mind with those products in which they saw some celebrities. This is an untruthful trick utilized by the marketer to gain customers' attention. The advertisement objective is not just enthusiastically and promptly developed precise actions of a human, which also impacts the people globally. Nevertheless, that can be said that ads should be made in such a way that customers can easily recognize the disguised wrong claims of advertisement (Syed, 2014; Shabbir, Maalouf, Griessmair, Colmekcioglu, \& Akhtar, 2019).

The false and misleading television advertisements related to products and services affect the customers emotionally and mentally, which becomes a reason for negative consumer behavior. It is also observed that customers have limited resources and low purchasing power. However, when they buy the product, and when they use it, they are disappointed by the fraud, they get hurt financially, emotionally, and mentally. It is also observed that some customers are in depression, loneliness, and a strong feeling of dissatisfaction (Cawley et al., 2011). Numerous investigations have determined the behavior and attitude related to consumers regarding mendacious marketing. Similarly, another researcher evaluates the finding of commercials with unethical factors commenced by companies such as not reasonable prices, partial policies of credit, and specifically mendacious in commercials (Ali et al., 2011; Danciu, 2014).

Liligeto et al., (2014) the aim of the commercial is centrally focused on spreading awareness related to the products and delivering the information to its target market. Knowledge regarding the features of a product meaningfully affects the customer's behavior when there watch advertisements on a different medium of channels such as Print media, Tv, etc. Therefore, this is related to the advantages of the goods that are perceived, the price of the product perceived, perceived product quality, the perceived value of the product, perceived product country's origin, perceived company's image, and the perceived product's popularity. The substantial factor is the price that has an essential place in attaining and impacting customer behavior. Customers understand the worth and the value of the product, and so, they make efforts to defend their purchase at that particular price. The actual quality of the product also affects the perception of the consumers (Alhas, 2013; Hussain et al., 2020). 


\section{RESEARCH METHODOLOGY}

\section{Research Design and Sample Size}

This study is based on qualitative research, and the methodology is phenomenology which was selected to understand the impact of customer experiences regarding advertising and to describe the meaning of what all participants have in mutual as they encounter a phenomenon. It allows the author to put himself in the place of that person and then recognize the personal encounters of individuals. In which the interviews and behaviors of people are studied for the data collection and for outcomes exploratory analysis are also added in this study which contain the finding of unique aspects that have never been judged earlier (Manen, 1997).

Mittal suggested in (2015) that qualitative research includes oral examination and projective proficiency. Oral examination refers to a specific group, and comprehensive interviews and findings are considered to be valuable. Qualitative research aims to give enlightened and recognizing difficult issues of psychological and utmost valuable for replying to humanistic questions like "why"? And "how" (Marshall,1996).

The qualitative method of this study is phenomenology, and earlier studies are recommended different sample sizes some recommended sample size of qualitative research is $5-25$ further researchers recommended a minimum of 6 sample sizes. These suggestions can support a researcher should be based on when they are needed how many respondents, but finally, the essential number of respondents is based on a saturation point (Guest, Bunce \& Johnson, 2006; Creswell \& Creswell 2017).

The sample size of this study consists of six participants. To gain in-depth views of participants, six interviews have been conducted. In which all the participants are from different age groups and their backgrounds are also different. Two females were the lecturer in the university, and the other one was a student and from male one was a student and the other two from the private Bank. All persons are the consumers of local and branded products, and the participants were voluntarily interested in sharing their opinions and experiences with the phenomena of the research. On the other hand, selecting a sampling technique for this research is convenience non-random sampling. By the convenience sampling technique gather insight from an informant who is easily nearby to the researcher.

\section{Method and Data Collection}

The data gathered for this current study is of two types, the first is primary data collection, and the second is secondary data collection. The primary data collected by six participants was based on interviews in which particular participants were selected, and series of open-ended questions were developed which were asked by the interviewer one by one, and answers were written on a sheet of paper. Only three interviews were recorded as it was allowed by the interviewees while the others were not. The time for two interviews was 50 minutes, and the other was conducted in 40 minutes. The questions were carefully predetermined before the interview. After the data analysis, axial coding was developed and then selected coding, which identified six themes from the data.

The transcriptions require much time and in-depth knowledge to acquire pauses, 
speed, timings, tone of voice, but these modules can be problematic to compose down and correspondingly investigated (Bengtsson 2016).

\section{RESULT AND DISCUSSION}

The data checklist was prepared after interviewing the six customers, and all were completely described to through the participants and after that complete transcript was reviewed, systematized, and revised for data analysis and extract the themes from the data (Connelly \& Peltzer, 2016). The transcripts were well-organized in the form of tables, and six themes were identified that are dissatisfied customers, over-promising, negative word of mouth, financial losses, brand switching, and broken trust. The results are astonishing while going through this process, and results are being analyzed as per the customer's perspective. The customers amazingly tell some facts. These themes are described below and show the consumer's perspective and if marketer or businessmen will create an advertisement in an ethical way and according to consumer laws that will create strong customer relationship, profitability and also increase market shares (Mehta \& Mehta, 2017).

\section{Dissatisfied Customer}

As per the perception of participants that deceptive practices of marketing which brands do in their advertisement make customers dissatisfied because the knowledge about goods is not given correctly in the ads. Once the customer purchased the product, it gets dissatisfied with the results. Dissatisfied customers tend to be more sensitive and dangerous for the brand as well he can spread negative marketing about the brand and can cause massive damage as customer's loss and brand image (Huq, Nekmahmud \& Aktar, 2016). Dissatisfaction refers to the feeling of the customers, such as the brand is cheating on them. Moreover, it can be occurred to buy the products featured if they are mentioned incorrectly in the advertisements. Customers will not give a second chance until they have high loyalty as loyal to them

(Lanjekar \& Tilak, 2019).

\section{Over Promising}

Overpromising is the word that gives the wrong and inaccurate impression and delivers inappropriate messages through advertisement. This makes customer's expectations high towards the product, which is presented in the commercials. The statements which have untrue and high expectation elements tend to be mendacious marketing practices. An advertisement that has an element of misleading does impact severely on the customers. During the interview, the participant tells that ads that contain statements that are not lawful in real leads to be overpromising (Lellis, 2016).

Due to the over-promising ads, customers suffer from huge losses both emotionally and physiologically. As a result, they become more careful, more attentive, and more sensitive regarding the brand's every product. A single immoral statement can affect the entire product line of the brand. Because once the negative image builds in the customer's mind, they will start thinking that all the products would be the same. It will also affect the profit due to bad experiences and will stop purchasing from that brand. This happens mostly in those products which are on sale due to the wrong quality customer faces the lousy experience and discontinued using the particular brand (Zgheib, 2017). 


\section{Negative Word of Mouth}

Once the customers face the negative experience, it spreads the negative comments and statements about the brand to their friends, family, and in their surroundings as well as to the other customers who are the regular customers of the same brand build confusions. At the same time, they postpone or change purchase decisions, which can be a substantial loss for the brand as well (Stockman \& da Motta, 2020). Those companies who deliver untrue facts about the product are indirectly creating harmful practices. The undesirable promotions which can be done by dissatisfied customers make the brand's image very bad in the market. Interpretation of the product as it can give the customers that comfort which they only think about it is wrong because none of the good and services can give that pleasure and ease to the customers for a long time. These practices are wrong and not justified because these are unlawful and leads to mendacious advertisement (Zhang, Ko \& Carpenter, 2016).

\section{Lost Customer Relationship}

The company once does one of the substantial elements of the brand which makes the brand to be known through customers, but the deceptive advertisements lose its customer's relationship because customers never prefer to use the brand that created them. The customer's relationship is one of the essential elements of all the marketing components (Iqbal \& Siddiqui, 2019). The marketers can only survive in the environment of rivalry when they care about their customers, give importance to them, never lie to them, prefer to market based on moral values, and satisfied them through these stages. The interviewee shares that today's customers are very well aware of brands and their practices, and they are very much concerned about it too. Customers know which brands are cheating on them, and after analyzing, they stop purchasing their products and which breaks their relationship no matter how old it was (Arbak, Islam \& Al Rasyid, 2019).

\section{Financial Lose and Brand Switching}

Human emotions are considered to be the best trait of human life. Whenever we feel sad due to any incident, we never forget that incident in our entire life it same goes for the brand. When customers purchase any products by watching the ad and the benefits of the product, and after buying it they do not get the results as it was presented in the ad, then they feel that they have lost their money and their time. Expensive products or treatments require much money, but when these expensive products do not work, then customers switch towards the other brand due to their financial loss. Losing money and getting emotionally hurt is the most crucial and impact the customer's mind. Customers can never forget those experiences in which they lost their money and got emotionally hurt (Mullick, \& Abdin, 2016).

\section{Broken Trust}

When a customer trusts the brand, it builds loyalty which leads the brand to be reliable for other customers as well because they start sharing their experiences regarding the brand and can increase customers' share through their encounters. However, if that brand cheats on the customers it broke the customer's trust, and then the customer would never want to come back to that brand because a single bad experience is enough for the customers due to the other substitutes, they will prefer them. Expecting accurate information, correct specification, all 
original features about the product, and being honest with them from the brand is the right of customers. However, when they are not found, it breaks down their trust, and trust recovery is the most crucial to retain your customers for the brand. Making customers satisfied should not be only the objective of the brand, but retaining them successfully should also be the primary aim of the brand (Nahf, 2018).

\section{CONCLUSION}

This qualitative study explores the impact of deceptive marketing practices which lead to consumer behavioral skepticism. The finding is based on the literature review, and information gathered indicates that deceptive advertisements destroy the brand image. In today's world, deceptive advertisement is a pervasive problem for the consumer. Businesses and consumers must ethically do advertising. This study suggests that advertising companies or businessmen should focus on the ethical ways of advertising and avoid misleading claims with incorrect interpretations. Companies need to consider advertising rules and ethics regarding their advertisement. Unethical or deceptive advertisements negatively impact consumer behaviour. The businessman should follow the rules related to advertisement and also consumer protection laws.

\section{RECOMMENDATION}

As per the results that have been disclosed and after determining the behaviors of customers that are identified by interviews. There is various recommendation can be suggested such as brands can only have powerful equity if a businessman starts understanding the customer's minds, it will create a positive image and customer loyalty. In the age of globalization, customers are getting more aware and conscious regarding their purchase habits. When they realize that brands are cheating them or deceiving them through advertisement, they become more attentive regarding their purchasing activities. So, the brand's manager should be more attentive when they develop ads and their specification about the products. By this ethical practice of marketing companies can make their brand position strong as a result, satisfied customer starts to spread positive word of mouth. The marketer or brand manager should give priority to customers related to that brand because if there no customers it means that there is no brand.

\section{REFERENCES}

Aghakhani, H., \& Main, K. J. (2019). Can two negatives make a positive? Social exclusion prevents carryover effects from deceptive advertising. Journal of Retailing and Consumer Services, 47, 206-214.

Ahmad, W., \& Sun, J. (2018). Modeling consumer distrust of online hotel reviews. International Journal of Hospitality Management, 71, 77-90.

Alhas, N., \& Abdullahi, Y. S. (2013). Criminal and Unethical Behaviors in Organisations: Misuse of Assets and False or Misleading Advertising. Global Journal of Human-Social Science Research, 13(3), 01-09 
Ali, F., Raza, A., Izhar, S. U., Shoaib, M., Amin, W., Adnan, M., \& Mehmood, A. (2011). Attraction of Students towards Beauty Products. Australian Journal of Business and Management Research, 1(3), 104-108

Alshurideh, M., Al Kurdi, B., Abu Hussien, A., \& Alshaar, H. (2017). Determining the main factors affecting consumers' acceptance of ethical advertising: A review of the Jordanian market. Journal of Marketing Communications, 23(5), 513-532.

Amah, E., Ogunnaike, O. O., Ayeni, A. W., \& Ojo, M. (2017). A Thematic Analysis of Advertisement in the Telecommunication Industry. Binus Business Review, 8(3), 221-228.

Arbak, S., Islam, R., \& Al Rasyid, H. (2019). Relationship Between Advertisement and Purchase Intention on Halal Cosmetic Products in Malaysia. Humanities E Social Sciences Reviews, $7(3), 683-694$.

Ariyadasa, A. (2019). Misleading Consumers by Unfair Advertising; Competition Law in Sri Lanka (SL). Competition Law in Sri Lanka (SL) (May 16, 2019).

Au, A. K. M., \& Tse, A. C. B. (2019). Expectancy disconfirmation: effects of deviation from expected delay duration on service evaluation in the airline industry. Asia Pacific Journal of Marketing and Logistics, 31(1), 291-300.

Bengtsson, M. (2016). How to plan and perform a qualitative study using content analysis. Nursing Plus Open, 2, 8-14.

BinNooh, M. N., Khairi, K. F., Ab Aziz, M. R., Abdullah, M., \&Shukor, S. A. (2014). The Criteria and Challenges of Unethical Advertising. American Journal of Business, Economics and Management, 2(4), 88-93.

Cawley, J., Avery, R., \& Eisenberg, M. (2011). The effect of advertising and deceptive advertising on consumption: the case of over-the-counter weight loss products. Working Paper.

Chaudary, M. W. T., Ahmed, F., Gill, M. S., \& Rizwan, M. (2014). The determinants of purchase intention of consumers towards counterfeit shoes in Pakistan. Journal of Public Administration and Governance, 4(3), 20-38.

Chelliah, J., \& Swamy, Y. (2018). Deception and lies in business strategy. Journal of Business Strategy, 39 (6), 36-42.

Cohen, S. (2018). Manipulation and deception. Australasian Journal of Philosophy, 96(3), 483-497.

Connelly, L. M., \& Peltzer, J. N. (2016). Underdeveloped themes in qualitative research: Relationship with interviews and analysis. Clinical nurse specialist, 30(1), 52-57.

Costa, J. C. (2014). The impact of advertising on students: an empirical study of students from Goa. International Journal of Advanced Research in Management and Social Sciences, 3(12), 239-249. 
Creswell, J. W., \& Creswell, J. D. (2017). Research design: Qualitative, quantitative, and mixed methods approaches. Sage publications.

Danciu, V. (2014). Manipulative marketing: persuasion and manipulation of the consumer through advertising. Theoretical and Applied Economics, 21 (2 (591).

Filtenborg, A. F., Gaardboe, F., \& Sigsgaard-Rasmussen, J. (2017). Experimental replication: an experimental test of the expectancy disconfirmation theory of citizen satisfaction. Public Management Review, 19(9), 1235-1250.

Grimmelikhuijsen, S., \& Porumbescu, G. A. (2017). Reconsidering the expectancy disconfirmation model. Three experimental replications. Public Management Review, 19(9), 1272-1292

Guest, G., Bunce, A., \& Johnson, L. (2006). How many interviews are enough? An experiment with data saturation and variability. Field methods, 18(1), 59-82.

Halamata, A. N. (2013). Ethics in Advertisement and Its Impact on Women and Children. International Journal of Business and Management Invention, 2(6),1-4

Hayder, N. B. (2017). Deceptive Advertising and Purchase Behavior of University students: A Study on Skin-Care Products in Bangladesh. Global Journal of Management and Business Research, $17(2), 66-76$

Huq, S. M., Nekmahmud, M., \& Aktar, M. S. (2016). Unethical practices of advertising in Bangladesh: a case study on some selective products. International Journal of Economics, Finance and Management Sciences, 4(1), 10-19

Hussain, S., Melewar, T. C., Priporas, C. V., Foroudi, P., \& Dennis, C. (2020). Examining the effects of celebrity trust on advertising credibility, brand credibility and corporate credibility. Journal of Business Research, 109, 472-488.

Iqbal, S. and Siddiqui, DA (2019). The Impact of Deceptive Advertising on Customer Loyalty: A case of Telecommunication Industry in Karachi, Pakistan. International Journal of Industrial Marketing, 4(1), 39-69.

Iqbal, S., \& Siddiqui, D. A. (2019). The impact of deceptive advertising on Customer loyalty: A case of Telecommunication industry in Karachi, Pakistan. Iqbal, S. and Siddiqui, DA (2019). The Impact of Deceptive Advertising on Customer Loyalty: A case of Telecommunication Industry in Karachi, Pakistan. International Journal of Industrial Marketing, 4(1), 39-69.

James, O. (2007). Evaluating the expectations disconfirmation and expectations anchoring approaches to citizen satisfaction with local public services. Journal of Public Administration Research and Theory, 19(1), 107-123.

Jeeva, C. (2016). Impact of Misleading Advertisements: Issues and Remedies. Bonfring International Journal of Industrial Engineering and Management Science, 6(4), 155. 
Khan, S. K., Saeed, N., Feroz, M., Liaqaut, S., Khan, A., \& Jabeen, Z. (2015). Impact of deceptive marketing on consumers behavior: A case of cellular industry of Pakistan. Journal of Marketing and Consumer Research, 18(1), 91-100.

Kotler, P. (2011). Marketing insights from A to Z: 80 concepts every manager needs to know. John Wiley \& Sons.

Krstic, V., \& Saville, C. (2019). Deception (Under Uncertainty) as a Kind of Manipulation. Australasian Journal of Philosophy, 97(4), 830-835.

Lanjekar, K. K., \& Tilak, G. (2019). Study on Controversial Advertising in India. International Journal of Social Sciences, 8(2), 63-68.

Lellis, J. C. (2016). Waving the red flag: FTC regulation of deceptive weight-loss advertising 19512009. Health communication, 31(1), 47-59.

Liepinyte, M., \& Daugèlienè, R. (2012). Interrelation of misleading advertising and solutions of consumers: legal regulation and institutional background in Lithuania. European integration studies (6), 192-201.

Liligeto, R., Singh, G., \&Naz, R. (2014). Factors influencing Consumer Perception (CP) towards TV and newspaper advertising. Journal of Pacific Studies, 34(2), 63-86.

Lim, J. S., Chock, T. M., \& Golan, G. J. (2020). Consumer perceptions of online advertising of weight loss products: the role of social norms and perceived deception. Journal of Marketing Communications, 26(2), 145-165.

Mahmood, Z. (2013). Impact of Deceptive Advertisement on Consumer Psyche. World Applied Sciences Journal, 26(12), 1662-1667.

Maicibi, N. A., \& Abdullahi, Y. S. (2013). Criminal and Unethical Behaviours in Organisations: Misuse of Assets and False or Misleading Advertising. Global Journal of Human-Social Science Research (F): Political Science, 13(3), 1-0.

Manen, M. V. (1997). From meaning to method. Qualitative health research, 7(3), 345-369.

Marshall, M. N. (1996). Sampling for qualitative research. Family practice, 13(6), 522-526.

Mehta, D., \& Mehta, N. K. (2017). Advertisements Showing Children: An Ethical Perspective. Clear International Journal of Research in Commerce E Management, 8(8), 44-46.

Morgeson, F. V. (2012). Expectations, disconfirmation, and citizen satisfaction with the US federal government: Testing and expanding the model. Journal of Public Administration Research and Theory, 23(2), 289-305.

Mpinganjira, M., \& Maduku, D. K. (2019). Ethics of mobile behavioral advertising: Antecedents and outcomes of perceived ethical value of advertised brands. Journal of Business Research, 95, 464-478. 
Mullick, N. H., \& Abdin, S. (2016). A Conceptual Perspective on Brand Switching Behaviour of Consumers in Telecommunication Industry. Journal of Commerce and Trade, Society for Advanced Management Studies, 11(1), 50-58.

Nehf, J. P. (2018). Misleading and unfair advertising. In Handbook of Research on International Consumer Law, Second Edition. Edward Elgar Publishing.

Ohlhausen, M. K. (2014). Privacy challenges and opportunities: The role of the Federal Trade Commission. Journal of Public Policy Eं Marketing, 33(1), 4-9.

Passarini, P., Cavicchi, A., Santini, C., \& Mazzantini, G. (2017). Deceptive advertising and unfair commercial practices in the agri-food sector: The role of the Italian competition authority. British Food Journal, 119(8), 1781-1800.

Rao, A., \& Wang, E. (2015). Demand for "Healthy" Products: False claims in advertising.

Raziq, M. M., Ahmed, Q. M., Ahmad, M., Yusaf, S., Sajjad, A., \& Waheed, S. (2018). Advertising skepticism, need for cognition and consumers' attitudes. Marketing Intelligence E Planning, 36(6), 678-693.

Reichert, T., \& Lambiase, J. (Eds.). (2013). Sex in consumer culture: The erotic content of media and marketing. Routledge.

Sahni, N. S., \& Nair, H. S.(2020). Sponsorship Disclosure and Consumer Deception: Experimental Evidence from Native Advertising in Mobile Search. Marketing Science, 39(1), 5-32.

Sarah, K. S., \& Jenefa, L. (2020). Factors Influencing Consumer Buying Behaviour towards Mobile Phone. Studies in Indian Place Names, 40(1), 631-642.

Sayed, I. (2014). An Empirical Research on Misleading Advertisements and Its Impact on Consumer Buying Behaviour. In Second International Conference on Global Business, Economics, Finance and Social Sciences, Chennai, India, July (pp. 11-13).

Shabbir, H. A., Maalouf, H., Griessmair, M., Colmekcioglu, N., \& Akhtar, P. (2019). Exploring perceptions of advertising ethics: An informant-derived approach. Journal of Business Ethics, 159(3), 727-744.

Shahzad, M. K., \&Kausar, M. (2016). The influence of deceptive advertising on customer trust and loyalty: A Study of Telecom Sector in Pakistan.

Song, R., Kim, H., Lee, G. M., \& Jang, S. (2019). Does deceptive marketing pay? The evolution of consumer sentiment surrounding a pseudo-product-harm crisis. Journal of Business Ethics, $158(3), 743-761$.

Stockman, S., Van Hoye, G., \& da Motta Veiga, S. (2020). Negative word-of-mouth and applicant attraction: The role of employer brand equity. Journal of Vocational Behavior, 118, 103368. 
Ukaegbu, R. C. (2020). Deceptive Advertising and Consumer Reaction: A Study of Delta Soap Advertisement. Open Access Library Journal, 7(3), 1-7.

Ukaegbu, R. C. (2020). Deceptive Advertising and Consumer Reaction: A Study of Delta Soap Advertisement. Open Access Library Journal, 7(3), 1-7.

Van Ryzin, G. G. (2006). Testing the expectancy disconfirmation model of citizen satisfaction with local government. Journal of Public Administration Research and Theory, 16(4), 599-611.

Zedan, M., \& Salem, Y. (2016). Factors affecting consumer attitudes, intentions and behaviors toward SMS advertising in Palestine. Indian Journal of Science and Technology, 9(4), 1-14.

Zgheib, P. W. (2017). Advertising deceit: Manipulation of information, false advertising, and promotion. In Advertising and branding: Concepts, methodologies, tools, and applications (pp. 1482-1494). IGI Global.

Zhang, X. J., Ko, M., \& Carpenter, D. (2016). Development of a scale to measure skepticism toward electronic word-of-mouth. Computers in Human Behavior, 56, 198-208. 